\title{
A meta-analysis of efficacy and tolerability of buprenorphine for the relief of cancer pain
}

\author{
Cho Naing ${ }^{1,2^{*}+}$, Peng Nam Yeoh ${ }^{1+}$ and Kyan Aung ${ }^{1}$
}

\begin{abstract}
This study aimed to synthesize available evidence on the analgesic efficacy of buprenorphine in treating cancer pain and related adverse effects. We searched electronic databases for randomized controlled trials, assessing the efficacy of buprenorphine, regardless of delivery system. The primary endpoints were patient-reported 'pain intensity' and 'pain relief'. Statistical heterogeneity among included studies was assessed with the $P$ test. The summary relative risk (RR) and 95\% Cl were derived, if two or more studies reported the similar outcome. Sixteen RCTs $(n=1329)$ with buprenorphine were included: 8 transdermal (TD), 5 sublingual (SL), 2 intramuscular injection (IM) and 1 subcutaneous infusion (SC) studies; with both SL and IM routes being assessed in one study. Only a few studies reported the same outcome in a similar way, creating difficulty for pooling of the outcome data. Many studies had a high risk of bias. In 2 studies $(n=241)$, the 'global impression change' was significantly different between TD buprenorphine and the combined placebo and morphine (RR 1.35, 95\% Cl 1.14-1.59; $P^{2}$ : 42\%); the 'number-needed-to-treat' (NNT) was 4.9 (95\% Cl: 3.1-10.9). In 2 studies ( $n=331$ ), 'requirement for rescue SL buprenorphine' was comparable between TD buprenorphine and placebo (RR 1.25, 95\% Cl 0.71-2.18; $\left.P^{2}: 40 \%\right)$. In 2 studies $(n=141)$, 'incidence of nausea' was less in TD buprenorphine (RR: $0.38,95 \% \mathrm{Cl}: 0.2-0.71, I^{2}: 0 \%, \mathrm{NNT}: 9.3,5.6-28.5$ ). Due to the small number of participants in a small number of studies, the results of the present review provide insufficient evidence to position adequately the use of buprenorphine in treatment of cancer pain. Large multicenter RCTs that compare TD buprenorphine with standard analgesic treatment is needed to position TD buprenorphine in the therapeutic armamentarium of cancer pain treatment.
\end{abstract}

Keywords: Buprenorphine; Efficacy; Randomized controlled trials; Meta-analysis

\section{Introduction}

Worldwide cancer is one of the leading causes of morbidity and mortality. In 2012 new cases of cancer was estimated to be 14.1 million per year (ICRC 2012) and is expected to climb to 19.3 million per year in 2025 (WHO 2011; ICRC 2012). The estimated cancer-related deaths was 8.2 million in 2012 (ICRC 2012). The majority of all cancers (56.8\%) and cancer deaths (64.9\%) in 2012 occurred in less developed countries (ICRC 2012). When there is local and metastatic spread of cancer, complications arise and pain is an inevitable outcome. Over the years, the use of opioids has been the mainstay for treating cancer pain (Hanks 1991).

The WHO recommended the concept of 'a threestep analgesic ladder' in the treatment of cancer pain

\footnotetext{
*Correspondence: cho3699@gmail.com

${ }^{\dagger}$ Equal contributors

'International Medical University, Kuala Lumpur, Malaysia

${ }^{2}$ School of Postgraduate Studies, International Medical University, Kuala Lumpur 57000, Malaysia
}

\section{Springer}

(c) 2014 Naing et al.; licensee Springer. This is an Open Access article distributed under the terms of the Creative Commons Attribution License (http://creativecommons.org/licenses/by/2.0), which permits unrestricted use, distribution, and reproduction in any medium, provided the original work is properly credited.

(Levy 1996; WHO 1996). In step III of the analgesic ladder, morphine is the drug of choice for the management of moderate to severe cancer pain (WHO 1996, 2009; Quigley 2004). However, published studies had reported that adequate analgesia with morphine was not achieved in $10-30 \%$ of patients with cancer pain (Cherny et al. 2001; Wiffen et al. 2003; Quigley 2004; WHO 2009). Along this line, alternatives to morphine which are novel formulations of existing drugs (Hanks et al. 2001) are available.

Buprenorphine, synthesized in the late 1960s was used as a parenteral analgesic since 1978. Buprenorphine is also available in the forms of sublingual (SL) tablets or transdermal (TD) patches. It is a partial agonist at $\mu$ opioid receptors (MOR) (Yaksh and Wallace 2011), an antagonist at kappa opioid receptors (KOR) (Yaksh and Wallace 2011) and a partial agonist at opiate receptorlike receptor (ORL-1) (Lutfy and Cowan 2004). 
In the treatment of opioid dependence, a Cochrane review showed that maintenance dose was less effective with buprenorphine than methadone. (Mattick et al. 2008). Thus, it is of immense value to provide evidence of the efficacy and safety of opioid analgesics for cancer pain.

Reviews which addressed the efficacy of TD buprenorphine are available for chronic treatment of moderate to severe pain (Deandrea et al. 2009; Tassinari et al. 2011) and for cancer pain (Wolff et al. 2012; Naing et al. 2013). All these reviews assessed TD buprenorphine, excluding other non-TD administration of buprenorphine. A review covering buprenorphine delivered via any route for treating cancer pain would be more informative and valuable in comparison. Taken collectively, the objectives of the present study were to synthesize available evidence on the analgesic efficacy of buprenorphine in treating cancer pain and on the drug-related adverse effects.

\section{Methods}

Literature search

We searched electronic databases of MEDLINE, EMBASE, CINAHL and the Cochrane Library up to July 2013. We also searched the reference sections of the selected studies and relevant reviews for any additional studies which were not found in the initial search. We followed the search terms used in our earlier publication (Naing et al. 2013). The search strategies were a combined search terms for the cancer and for buprenorphine. The searched term for cancer included; "cancer, human" [MeSH] OR "malignancy" OR "cancer, gastrointestinal" OR "cancer, bladder" Or "cancer, breast" OR "cancer, stomach" OR "cancer, colon" OR "cancer, prostate" OR "cancer, lung". Searched term for buprenorphine included; "buprenorphine" OR "bupre".

\section{Selection criteria}

We included studies following the PICOS criteria; (1) (Participants, P): those patients with cancer, regardless of age, gender, type of cancer and healthcare settings; (2) (Intervention, I) studies where participants in one arm should use buprenorphine, regardless of route of administration; (3) (Comparison, C) studies which compared the efficacy of buprenorphine with placebo, other opioid analgesic or no treatment; (4) (Outcome, O) the proportion of participants with the changes in intensity of cancer pain; and (5) (Study design, S): RCT in which efficacy of buprenorphine preparations was assessed in cancer patients.

Studies were excluded if they (i) were not RCTs, (ii) did not assess pain as an outcome measure, (iv) were carried out with fewer than 10 participants, (v) were conducted with those who had pain with the absence of cancer, (vi) were assessed where pain was related to treatments (chemotherapy-induced neuropathic pain), or (vii) were assessed with pain due to surgical procedures. We also excluded studies on pharmacodynamics, pharmacoeconomics, case reports and conferences reports.

\section{Data extraction and risk of bias assessment}

Two authors independently screened all citations and retrieved article(s) which were considered eligible for the present review. The two authors independently extracted data from the studies, using a piloted-data extraction form. The following information was collected: study design, sample size, participant characteristics, cancer status, drugs and their dosing, duration of study and follow-up, analgesic outcome measures, adverse events (AE's) and serious adverse events (SAE's). We resolved any discrepancy by discussion.

The two authors independently determined quality of studies following the Cochrane risk of bias tool (Higgins and Green 2011). The domains assessed were 'random sequences generation', 'allocation concealment', 'blinding of participants and/or outcome assessment' and they were categorized as 'low' 'high' or 'unclear' risk of bias. Discrepancies were resolved by consensus.

\section{Statistical analysis}

The primary outcomes of interest were 'patient-reported pain intensity' and 'pain relief' as measured by validated scales such as verbal rating scales (VRS), visual-analogue scales (VAS) and numerical rating scales (NRS). The secondary outcomes were incidence of buprenorphinerelated AE and SAE. We performed meta-analysis when 2 or more individual studies were suitable for pooling on the basis of similarity. Dichotomous data were compared using a relative risk (RR) and respective 95\% confidence interval (CI). We assessed statistical heterogeneity by $I^{2}$ test; a value of $I^{2}>50 \%$ indicated substantial heterogeneity (Higgins and Green 2011). If there was substantial heterogeneity among studies, we used the DerSimonian and Laird random effect model when pooling data and calculated summary RR and respective 95\% CI. We also reported the number-needed-to-treat (NNT) for significantly different outcome. In order to test the robustness of our results, we reanalyzed the effect estimates by excluding individual studies from the meta-analysis (leave-one-out sensitivity analysis). For an assessment of reporting bias, we visually inspected the funnel plots. However, asymmetrical funnel plot may be considered due to other possible bias such as difference in methodological quality among studies (Higgins and Green 2011).

Data entry and analyses were done using RevMan Version $5 \cdot 2$ (The Nordic Cochrane Centre, Copenhagen). The present review has been reported according to the preferred reporting items for systematic reviews and meta-analyses 
(PRISMA) (Moher et al. 2009) (Additional file 1). A protocol of this study is available (Naing et al. 2012).

\section{Results}

Figure 1 shows the summary of study selection process. The literature search yielded 984 citations. Thirty six that examined the efficacy of buprenorphine were potentially relevant. A total of 16 studies $(n=1329)$ with four different routes of administration (subcutaneous, SL, IM, TD) were identified for the present review.

\section{Characteristics of the included studies (Table 1)}

Buprenorphine was applied TD in 8 studies, SL in 5 studies, IM in 2 studies and subcutaneous infusion (SC) in one study. Both SL and IM routes were assessed in one study (Dini et al. 1986). Both SC and IM routes were assessed in one study (Noda et al. 1989). The majority of the included studies (10/16: 62.5\%) were with the sample size less than 100 (ranges: 17-189). The comparator drugs included placebo, pentazocine, morphine, TD fentanyl and tramadol. Six studies were cross-over studies with each patient serving as his/her own control, while 9 studies were parallel-group comparisons and one study was within dose comparison. In accordance with the definition of enriched described elsewhere (Straube et al. 2008), three studies were completely enriched (Bohme and Likar 2003; Sorge and Sittl 2004; Poulain et al. 2008) and one study was partially enriched (Aurilio et al. 2009). Reported outcomes in the i analysed studies included a number of validated scales subjectively used for pain intensity and/or pain relief (e.g. VAS, VRS, NRS, questionnaires), requirement for rescue drugs, duration of pain-free sleep and presence of AE's and SAE's. As several different pain scoring systems were employed in these studies, a comprehensive comparison could not be made between all of them.

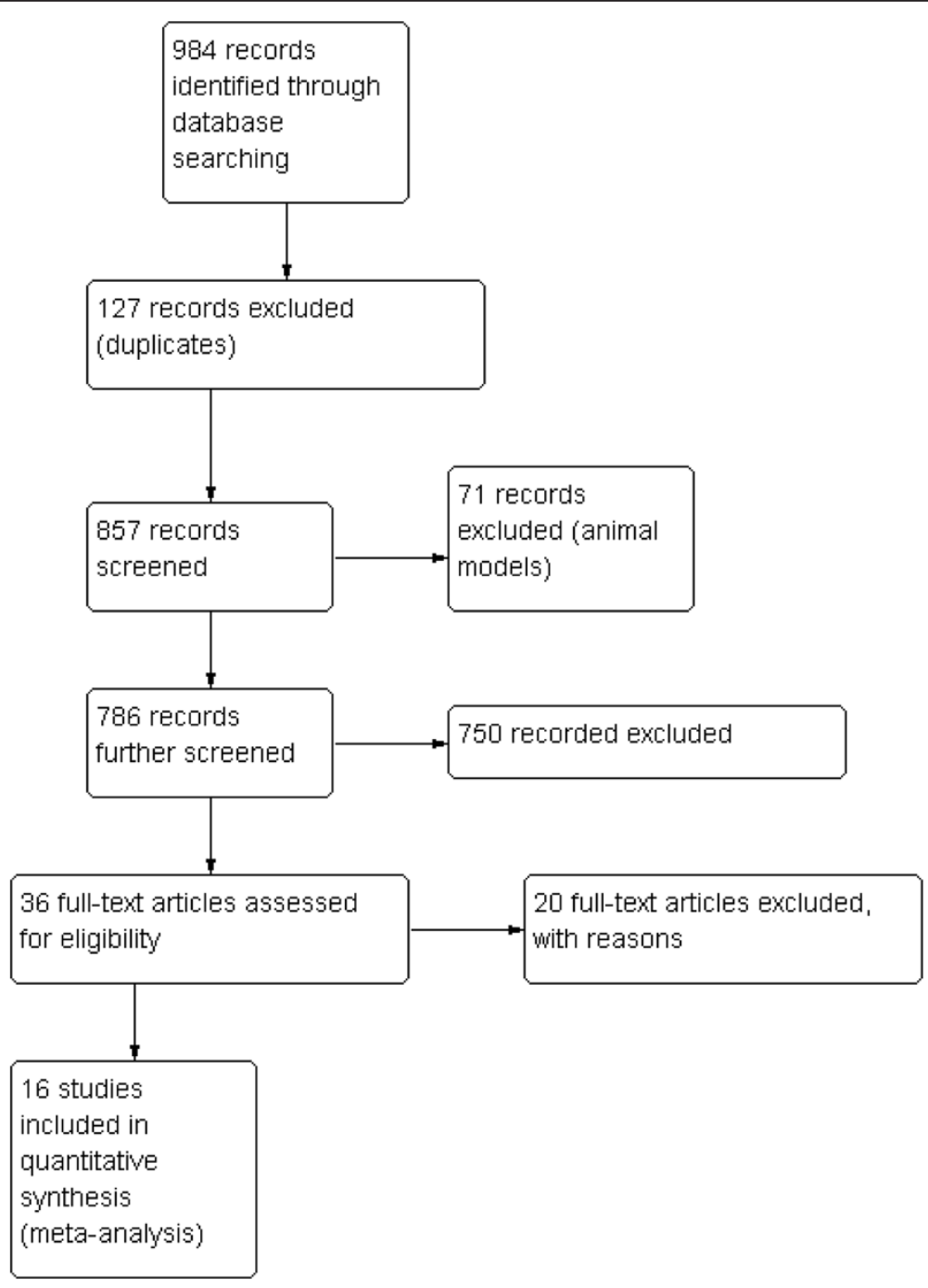

Figure 1 Study flow diagram. 
Table 1 Characteristics of the included studies

\begin{tabular}{|c|c|c|c|c|c|c|c|c|}
\hline $\begin{array}{l}\text { First author, } \\
\text { publication } \\
\text { year }\end{array}$ & Country & $\begin{array}{l}\text { Features of } \\
\mathrm{RCT}\end{array}$ & $\begin{array}{l}\text { Sample } \\
\text { size (M; F) }\end{array}$ & Mean age & Route & Comparator drugs & $\begin{array}{l}\text { Outcome } \\
\text { measurement }\end{array}$ & Remarks \\
\hline Aurilio 2009 & Italy & Cross-over & $32(7: 15)$ & $62(42-78)$ & TD & TD fentanyl & VAS, PPI, PRI & $\mathrm{ITT}$ \\
\hline Bohme 2003 & $\begin{array}{l}\text { Austria, } \\
\text { Germany, } \\
\text { Hungary }\end{array}$ & Multicenter & $151(70: 81)$ & $60.6( \pm 12.2)$ & TD & Placebo & VRS, responder & $\begin{array}{l}\text { Complete enriched; } \\
\text { mixed with non-cancer } \\
\text { \& cancer patients }\end{array}$ \\
\hline Bono 1997 & Italy & Cross-over & $60(44: 16)$ & $61.4(40-84)$ & $\mathrm{SL}$ & Oral tramadol & VAS, KSI & Non-English \\
\hline Brema 1996 & Italy & Multicenter & $131(86: 45)$ & & SL & Oral tramadol & VAS, KSI & Non-English \\
\hline De Conno 1987 & Italy & Cross-over & 91 & & SL & Oral pentazocine & Pain relief, KSI & Non-English \\
\hline Dini 1986 & Italy & Single centre & $42(21 ; 21)$ & $0.3 \mathrm{mg}$ & $S L \& I M$ & $\begin{array}{l}\text { Oral pentazocine } \\
\& \text { IM pentazocine }\end{array}$ & Pain reduction. PI & Non-English \\
\hline Kjaer 1982 & Denmark & Single centre & $27(13: 14)$ & $60(41-71)$ & $\mathrm{IM}$ & IM morphine & Pain reduction & \\
\hline Likar 2007 & Austria & $\begin{array}{l}\text { Cross-over, } \\
\text { open label }\end{array}$ & 17 & $61.6( \pm 11.5)$ & TD & $\begin{array}{l}\text { TD buprenorphine } \\
\text { (4day vs } 3 \text { day regimen) }\end{array}$ & $\mathrm{Pl}$ & $\begin{array}{l}\text { A subset of cancer } \\
\text { patients }\end{array}$ \\
\hline Noda 1989 & Japan & Single centre & 30 & range: $25-72$ & SC \& IM & Placebo & VAS & \\
\hline Pace 2007 & Italy & Open label & $52(27: 15)$ & $55( \pm 2.6)$ & TD & Morphine & $\mathrm{Pl}$ & Non-enriched \\
\hline Poulain 2008 & & Multicenter & 189 & $63(33-83)$ & TD & Placebo & $\mathrm{Pl}$ & $\begin{array}{l}\text { Enriched; calculated } \\
\text { sample size }\end{array}$ \\
\hline Sittl 2003 & $\begin{array}{l}\text { Austria, } \\
\text { Germany, } \\
\text { Netherland }\end{array}$ & $\begin{array}{l}\text { Multicenter, } \\
\text { multidose }\end{array}$ & $157(71: 86)$ & $58.7( \pm 11.8)$ & TD & Placebo & $\begin{array}{l}\text { Pain relief, PI, } \\
\text { satisfaction }\end{array}$ & 3 dosage of TD \\
\hline Sorge 2004 & $\begin{array}{l}\text { Germany, } \\
\text { Poland }\end{array}$ & $\begin{array}{l}\text { Multicenter, } \\
\text { multidose }\end{array}$ & 137 & $56( \pm 12.1)$ & TD & Placebo & VRS, & $\begin{array}{l}\text { Complete enriched; } \\
33 \% \text { cancer patients }\end{array}$ \\
\hline Taguchi 1982 & Japan & Cross-over & 31 & & IM & IM pentazocine & $\mathrm{Pl}$ & Non- English \\
\hline Ventafridda 1983 & Italy & Cross-over & $60(42: 18)$ & $>18$ & $\mathrm{SL}$ & Oral pentazocine & VAS, PI & VAS \\
\hline Wirz 2009 & Germany & Multidrug & $174(98: 76)$ & $65.3( \pm 10.7)$ & $\mathrm{TD}$ & Oral hydromorphone & $\mathrm{Pl}$, rescue & Prospective \\
\hline
\end{tabular}

non-English: non-English language publication; ITT: intention-to-treat analysis; IM : intramuscular injection; KSI: NRS: PPI: PRI: Pain rating index; SC: subcutaneous administration; SL: sublingual administration; TD: transdermal administration; rescue: requirement of rescue drug; VAS: VRS, : Mean age: Mean age in year $( \pm$ SD or range); cross-over: cross-over studies; multidrug: more than 1 comparator drug; Responders; a composite scale; PI: pain intensity.

\section{Risk of bias}

Overall, many studies had high risk of bias (Table 2). Blinding of participants or outcome assessment was done in 4 studies (Bohme and Likar 2003; Sorge and Sittl 2004; Poulain et al. 2008; Aurilio et al. 2009). Most of the studies $(87.5 \%)$ had short intervention duration ( $\leq 15$ days).

\section{Efficacy estimation (Table 3)}

\section{TD buprenorphine}

Eight studies examined the use of TD buprenorphine for cancer pain (Bohme and Likar 2003; Sittl et al. 2003; Sorge and Sittl 2004; Likar et al. 2007; Pace et al. 2007; Poulain et al. 2008; Aurilio et al. 2009; Wirz et al. 2009). In 2 studies $(n=241)$ (Pace et al. 2007; Poulain et al. 2008), 'global impression of change' was significantly different between TD buprenorphine and a combined comparator (placebo and morphine) (RR:1.35, 95\% CI:1.14-1.59, $\left.I^{2} ; 42 \%\right)$; the NNT was 4.9 (3.1-10.9).
Two studies $(\mathrm{n}=288)$ (Bohme and Likar 2003; Sittl et al. 2003) assessed assessed the number of responding patients. Responders were defined as those whose pain relief was at least satisfactory at all determination points (excluding the final examination) and who took a mean of $0.2 \mathrm{mg}$ per day or less of SL buprenorphine on day 7-12 (Bohme and Likar 2003); the efficacy was more pronounced in TD buprenorphine $52.5 \mu \mathrm{g} / \mathrm{h}$ (RR:1.83, 95\% CI:1.12-2.99, $\left.I^{2} ; 64 \%\right)$ and $70 \mu \mathrm{g} / \mathrm{h}$ (RR:1.87, 95\% CI:1.17-3.0, $I^{2} ; 0 \%$ ). In 2 studies (Bohme and Likar 2003; Sorge and Sittl 2004), 'the duration of pain free sleep' (> $6 \mathrm{hrs}$ ) was significantly different between TD buprenorphine and placebo (RR: 3.02, 95\% CI: 1.12-8.17; $\left.I^{2}: 0 \%\right)$. Two studies $(\mathrm{n}=331)$ (Sittl et al. 2003; Sorge and Sittl 2004) reported a comparable requirement for rescue SL buprenorphine between TD buprenorphine and placebo (RR: 1.25 , 95\% CI: 0.71-2.18; $I^{2}: 40 \%$ ).

\section{SL buprenorphine}

Five studies examined SL buprenorphine in treating cancer pain (Dini et al. 1986; Brema et al. 1996; De Conno 
Table 2 Risk of bias of the included studies judged by the review authors

\begin{tabular}{|c|c|c|c|c|c|}
\hline $\begin{array}{l}\text { First author, } \\
\text { publication year }\end{array}$ & $\begin{array}{c}\text { Random sequence } \\
\text { generation }\end{array}$ & $\begin{array}{c}\text { Allocation } \\
\text { concealment }\end{array}$ & $\begin{array}{l}\text { Blinding of } \\
\text { participants }\end{array}$ & $\begin{array}{c}\text { Blinding of outcome } \\
\text { assessment }\end{array}$ & Duration \\
\hline Aurilio 2009 & Unclear & High & Unclear & Unclear & Unclear \\
\hline Bohme 2003 & Unclear & Unclear & Low & Low & Unclear \\
\hline Bono 1997 & Low & Unclear & Low & Unclear & Unclear \\
\hline Brema 1996 & Unclear & Unclear & Unclear & Unclear & Low \\
\hline De Conno 1987 & Unclear & Unclear & Unclear & Unclear & Unclear \\
\hline Dini 1986 & Unclear & Unclear & Low & Unclear & Unclear \\
\hline Kjaer 1982 & Unclear & High & Unclear & Low & Unclear \\
\hline Likar 2007 & Unclear & Low & High & High & Low \\
\hline Noda 1989 & Unclear & Unclear & Unclear & Unclear & High \\
\hline Pace 2007 & Low & Unclear & Unclear & Unclear & Unclear \\
\hline Poulain 2008 & Low & Low & Low & Unclear & Unclear \\
\hline Sittl 2003 & Unclear & Unclear & Unclear & Unclear & High \\
\hline Sorge 2004 & Low & High & High & Unclear & Unclear \\
\hline Taguchi 1982 & Unclear & Unclear & Low & Unclear & Unclear \\
\hline Ventafridda 1983 & Unclear & Unclear & Unclear & Unclear & Unclear \\
\hline Wirz 2009 & Low & Unclear & High & High & High \\
\hline
\end{tabular}

Low: low risk of bias; high: high risk of bias; Unclear: Unclear risk of bias.

et al. 1987; Ventafridda et al. 1983; Bono and Cuffari 1997). There were insufficient data for pooled analysis. In one study ( $\mathrm{n}=21)$ (Dini et al. 1986), 'any pain improvement' was not significantly different between SL buprenorphine and pentazocine or tramadol (RR:2.29, 95\% CI: 0.24-21.55).

\section{IM buprenorphine}

Three studies (Kjaer et al. 1982; Taguchi 1982; Dini et al. 1986) assessed the use of IM buprenorphine in patients with cancer pain. Due to inconsistency in data reporting and/or insufficient data, it was not possible to summarize the estimates. In 2 studies (Taguchi 1982; Dini et al. 1986), 'pain relief' was significantly better with IM buprenorphine $0.2 \mathrm{mg}$ single dose (RR:3.7, 95\% CI:1.72-7.93, $I^{2}$ : 0\%) or IM buprenorphine $0.3 \mathrm{mg}$ single dose (RR:3.03, 95\% CI:1.4-6.54, $\left.I^{2}: 0 \%\right)$ than in IM pentazocine group.

\section{SC administration}

One study (Noda et al. 1989) reported that the use of SC buprenorphine at the rate of $4 \mathrm{~g} / \mathrm{kg} /$ day for 48 hour in cancer patients gave satisfactory pain relief without serious complication. However, as the findings were based on uncontrolled series of only 30 patients, it should be interpreted with caution.

\section{Frequency of $A E^{\prime} s$}

Overall, AE's were not consistently reported across studies. In 2 studies $(\mathrm{n}=171)$ (Pace et al. 2007; Wirz et al. 2009), 'incidence of nausea' was significantly lower in TD buprenorphine than in morphine (RR: 0.38, 95\% CI: 0.2$\left.0.71, I^{2}: 0 \%\right)$. In 2 studies ( $\mathrm{n}=294$ ) (Sittl et al. 2003; Pace et al. 2007), 'skin reaction' was comparable between TD buprenorphine and hydromorphone (RR:1.42, 95\% CI: $\left.0.73-2.76, I^{2}: 0 \%\right)$. Also, in combining 2 studies $(\mathrm{n}=189)$ (Sittl et al. 2003; Sorge and Sittl 2004), incidence of CNSrelated events' was comparable between TD buprenorphine and comparator (i.e. placebo or hydromorphone) (RR:0.74, 95\% CI:0.33-1.66, $\left.I^{2}: 0 \%\right)$.

Of the five studies with SL buprenorphine, 3 studies reported AE's. However, it was not consistently reported in these studies. In 2 studies $(n=141)$ (Dini et al. 1986; De Conno et al. 1987), 'incidence of vomiting' was comparable between SL buprenorphine and pentazocine (RR: 1.28, 95\% CI: $\left.0.6-2.72, I^{2}: 0 \%\right)$. In 3 studies $(\mathrm{n}=261)$ (Dini et al. 1986; De Conno et al. 1987; Bono and Cuffari 1997), 'incidence of CNS-related events' was comparable between SL buprenorphine and tramadol or pentazocine (RR: 0.89, 95\% CI: 0.16-4.95, $I^{2}$ : 64\%).

AE's were not consistently reported in 3 studies with the use of IM buprenorphine.

A subset of study $(n=21)$ reported that none $(0 / 11)$ was intolerable with AE's in IM buprenorphine, but $20 \%$ $(2 / 10)$ in IM pentazocine (Dini et al. 1986).

In a study $(\mathrm{n}=30)$, AE's were fewer in SC buprenorphine than in placebo (Noda et al. 1989). In 2 studies $(\mathrm{n}=288)$ (Bohme and Likar 2003; Sorge and Sittl 2004), 'incidence of withdrawals' was comparable between TD buprenorphine and placebo (RR: 1.26, 95\% CI:0.48-3.31). In 2 studies $(n=201)$ (Brema et al. 1996; Bono and Cuffari 
Table 3 Comparative efficacy of buprenorphine

\begin{tabular}{|c|c|c|c|c|c|}
\hline \multirow[t]{2}{*}{ Description } & \multirow{2}{*}{$\begin{array}{l}\text { Number of studies } \\
\text { (study included) }\end{array}$} & \multicolumn{2}{|l|}{ Participants } & \multirow[t]{2}{*}{ RR (95\% CI) } & \multirow[t]{2}{*}{ Remark } \\
\hline & & $\begin{array}{l}\text { With outcomes/total } \\
\text { (buprenorphine group) }\end{array}$ & $\begin{array}{l}\text { With outcomes/total } \\
\text { (comparator) }\end{array}$ & & \\
\hline \multicolumn{6}{|l|}{ TD route } \\
\hline $\begin{array}{l}\text { Global impression of } \\
\text { change }\end{array}$ & $\begin{array}{l}2 \text { (Poulain et al. 2008; } \\
\text { Pace et al. 2007) }\end{array}$ & $96 / 120$ & $72 / 121$ & $\begin{array}{l}1.35(1.14-2.59) \\
P^{2}: 42 \%\end{array}$ & $\begin{array}{l}\text { NNT: } 4.9 \\
(3.1-10.9)\end{array}$ \\
\hline Responders $35.5 \mu \mathrm{g} / \mathrm{h}$ & $\begin{array}{l}2 \text { (Bohme and Likar 2003; } \\
\text { Sittl et al. 2003) }\end{array}$ & $27 / 76$ & $17 / 75$ & $\begin{array}{l}1.58(0.94-2.66) ; \\
P^{2}: 39 \%\end{array}$ & \\
\hline Responders $52.5 \mu \mathrm{g} / \mathrm{h}$ & $\begin{array}{l}2 \text { (Bohme and Likar 2003; } \\
\text { Sittl et al. 2003) }\end{array}$ & $37 / 75$ & $17 / 75$ & $\begin{array}{l}1.83(1.12-2.99) \\
P: 64 \%\end{array}$ & $\begin{array}{l}\text { NNT: } 5.3 \\
(3.06-24.09)\end{array}$ \\
\hline Responders $70 \mu \mathrm{g} / \mathrm{h}$ & $\begin{array}{l}2 \text { (Bohme and Likar 2003; } \\
\text { Sittl et al. 2003) }\end{array}$ & $34 / 87$ & $17 / 75$ & $\begin{array}{l}1.87(1.17-3) \\
P: 0 \%\end{array}$ & $\begin{array}{l}\text { NNT: } 5.03 \\
(2.98-18.6)\end{array}$ \\
\hline $\begin{array}{l}\text { Rescue SL } \\
\text { buprenorphine }\end{array}$ & $\begin{array}{l}2 \text { (Sorge and Sittl 2004: } \\
\text { Sittl et al. 2003) }\end{array}$ & $79 / 247$ & $23 / 84$ & $\begin{array}{l}1.25(0.71-2.18) \\
P: 40 \%\end{array}$ & \\
\hline $\begin{array}{l}\text { Requirement of } \\
\text { prophylactic } \\
\text { antiemetics }\end{array}$ & $\begin{array}{l}2 \text { (Sorge and Sittl 2004: } \\
\text { Sittl et al. 2003) }\end{array}$ & $24 / 129$ & $53 / 110$ & $\begin{array}{l}0.63(0.43-0.9) ; \\
P_{:}: 4 \%\end{array}$ & $\begin{array}{l}\text { NNT: } 3.8 \\
(2.4-8.4)\end{array}$ \\
\hline $\begin{array}{l}\text { Requirement } \\
\text { of laxatives }\end{array}$ & $\begin{array}{l}2 \text { (Sorge and Sittl 2004: } \\
\text { Wirz et al. 2009) }\end{array}$ & $45 / 151$ & $70 / 160$ & $\begin{array}{l}1.03(0.8-1.32) \\
P: 69 \%\end{array}$ & \\
\hline Nausea & $\begin{array}{l}2 \text { (Pace et al. 2007; } \\
\text { Wirz et al. 2009) }\end{array}$ & $11 / 87$ & $28 / 84$ & $\begin{array}{l}0.38(0.2-0.71) \\
P^{2}: 0 \%\end{array}$ & $\begin{array}{l}\text { NNT: } 9.3 \\
(5.6-28.5)\end{array}$ \\
\hline Constipation & $\begin{array}{l}2 \text { (Aurilio et al. 2009; } \\
\text { Wirz et al. 2009) }\end{array}$ & $32 / 77$ & $33 / 71$ & $\begin{array}{l}0.89(0.55-1.17) \\
P^{2}: 0 \%\end{array}$ & TD fentanyl \\
\hline Constipation & $\begin{array}{l}2 \text { (Pace et al. 2007; } \\
\text { Wirz et al. 2009) }\end{array}$ & $30 / 87$ & $36 / 84$ & $\begin{array}{l}0.89(0.55-1.17) \\
P^{2}: 81 \%\end{array}$ & Morphine \\
\hline CNS- related AEs & $\begin{array}{l}2 \text { ((Pace et al. 2007; } \\
\text { Sittl et al. 2003) }\end{array}$ & $12 / 116$ & $9 / 73$ & $\begin{array}{l}0.74(0.33-1.66) ; \\
P^{2}: 0 \%\end{array}$ & \\
\hline Skin related AEs & $\begin{array}{l}2 \text { (Sorge and Sittl 2004: } \\
\text { Sittl et al. 2003) }\end{array}$ & $38 / 209$ & $9 / 85$ & $\begin{array}{l}1.42(0.73-2.76) \\
P: 16 \%\end{array}$ & \\
\hline SAEs Deaths & $\begin{array}{l}2 \text { (Bohme and Likar 2003; } \\
\text { Sittl et al. 2003) }\end{array}$ & $3 / 155$ & $1 / 75$ & $\begin{array}{l}1.48(0.23-9.66) ; \\
P^{2}: 0 \%\end{array}$ & \\
\hline \multicolumn{6}{|l|}{ IM route } \\
\hline $\begin{array}{l}\text { Any pain improvement } \\
\text { (with } 0.3 \mathrm{mg} \text { dose) }\end{array}$ & $\begin{array}{l}2 \text { (Dini et al. 1986; } \\
\text { Taguchi 1982) }\end{array}$ & $22 / 42$ & $6 / 34$ & $\begin{array}{l}3.03(1.4-6.54) \\
P^{2}: 0 \%\end{array}$ & \\
\hline $\begin{array}{l}\text { Any pain improvement } \\
\text { (with } 0.2 \mathrm{mg} \text { dose) }\end{array}$ & $\begin{array}{l}2 \text { (Dini et al. 1986; } \\
\text { Taguchi 1982) }\end{array}$ & $23 / 35$ & $6 / 34$ & $\begin{array}{l}3.7(1.72-7.93) \\
P^{2}: 0 \%\end{array}$ & \\
\hline
\end{tabular}

AE's: adverse events, SAE's: Serious adverse events; CNS: central nervous system; IM : intramuscular injection; NNT: number-needed-to treat; RR: relative risk; SL: sublingual administration; TD: transdermal administration.

1997), incidence of withdrawals was also comparable between SL buprenorphine and oral tramadol (RR: 4.26, 95\% CI:0.25-73.96). In 2 studies $(\mathrm{n}=230)$ (Bohme and Likar 2003; Sittl et al. 2003), 'incidence of deaths' was comparable between TD buprenorphine and placebo (RR: 1.48, 95\% CI: 0.23-9.66).

\section{Other manifestations}

When patients were switched from one opioid to another (i.e. TD buprenorphine and TD fentanyl), the effects of analgesia and respiratory depressant of the second opioid (TD fentanyl in this review) was pronounced in some patients due to 'incomplete cross tolerance' (Levy 1996). AE's in patients in cross-over studies (Likar et al. 2007; Aurilio et al. 2009) were likely to be related to this important effect.

\section{Discussion}

The present review focused on the analgesic efficacy and tolerability of buprenorphine given by four different administration routes, SC, SL, IM or TD. We were unable to synthesize the estimations in the non-TD route of buprenorphine. This was due to the (1) small number of studies with small numbers of participants included; (2) different SL retention times (3) different eventual disposition of the SL tablet (swallowed or expectorated) (Robbie 1979; Reisfield and Wilson 2007); (4) different total doses of IM administrations or (5) different outcome measures. Overall, limitations in volume or surface area of SL space could cause drugs given via SL route to possibilities of ulceration, while the TD route is a non-invasive alternative to the oral route, particularly for stable pain states 
(Reisfield and Wilson 2007). The TD buprenorphine studies have provided some indication of pain improvement over short-term studies ( $\leqslant 15$ days follow- up). Moreover, AE's such as nausea and the requirement of prophylactic antiemetic were significantly lower in the TD buprenorphine group. Published non-Cochrane reviews have assessed TD buprenorphine in particular for non-cancer pain (Deandrea et al. 2009; Rossitto et al. 2009). In these reviews, incidences of nausea and treatment termination were significantly fewer in TD buprenorphine group than in TD fentanyl group. This is comparable to our findings, although variations in the number of studies and inclusion criteria do exist. Buprenorphine has the theoretical and potential advantage of being an opioid partial agonist with low abuse potential (Robbie 1979; Bohme and Likar 2003) and approximate equal bioavailability by the SL and TD routes (Skaer 2006).

Of note is the marked inequality between the groups of TD buprenorphine and placebo in a completely enriched study (Sorge and Sittl 2004). For instance, patients in the placebo group had a better starting condition and run-in phase. Also, more patients in the placebo group had received radiotherapy shortly before the onset of the study, contributing to their better pain status. Buprenorphine, when delivered via the TD route passively diffused into the systemic circulation (Bohme and Likar 2003; Sorge and Sittl 2004), providing a slower increase in serum concentration and no peak-andtrough effects as seen with the SL route (Yaksh and Wallace 2011; Al-Tawil et al. 2013). This is the reason why in many cases SL buprenorphine is used as rescue analgesic. As a matter of fact, TD buprenorphine is noninvasive and a suitable choice for cancer pain relief even in the presence of renal disease. It also has a beneficial ceiling effect for respiratory depression. A recent pharmacokinetic study has reported that the systemic exposure to TD buprenorphine was sufficiently similar between elderly ( $>75$ years) and younger (50-60 years) participants (Fudala et al. 2003). However, due to the heterogeneity of the published data and small sample sizes, the current meta-analysis has thus some limitations to provide sufficient evidence.

We acknowledge some limitations of this review. If not all, most of the included studies had small sample sizes $(<100$ in each arm), therefore it has inadequate power to detect significant difference. Due to the small number of participants in a small number of studies, the results of this review provide insufficient evidence to position adequately the use of buprenorphine in treatment of cancer pain. One third of studies with low risk of bias administered the TD buprenorphine (compared with placebo or other opioid analgesics) when pain levels were moderate or severe, ensuring that the studies were sensitive to detect pain-related outcomes. The preferred outcome measure ' $50 \%$ pain relief', was not reported in any included studies. Moreover, chronic pain studies (cancer pain in this case) of short duration ( $\lesssim 6$ weeks) have manifested greater treatment effects than those of longer duration ( $\approx 8$ weeks). Fourteen studies (87.5\%) were conducted over short intervention duration $(\lesssim 15$ days). Furthermore, severity of pain in cancer patients could be related to the result of a progression of the underlying diseases. Many cancer patients could have secondary metastases at the time of the studies (Likar et al. 2007). It was documented that marked escalation of opioid doses may be required (i.e. by 100 times or more) for those patients with solid tumours with metastases to the spine or central nervous system (Zhang et al. 2003). However, inadequate data precluded us from doing stratified analysis according to the tumour types. Furthermore, data were based on mixed groups (cancer pain and non-cancer pain) in some studies and we could not analyse cancer patients in such studies separately. The effect of such a selection bias was considered with caution. Hence, accuracy of effect estimation in the present review remains a concern.

\section{Conclusions}

In the treatment of cancer pain, low level of evidence exists for the benefit of buprenorphine particularly with TD administration. Large multicenter RCTs that compare TD buprenorphine with standard analgesic treatment is needed to position TD buprenorphine in the therapeutic armamentarium of cancer pain treatment. As the invasive route is relatively unfavourable for use in the treatment of patients with cancer pain, there is no justification for further research with IM buprenorphine.

\section{Additional file}

Additional file 1: Checklist.

\section{Abbreviations}

AE: Adverse event; CNS: Central nervous system; Cl: Confidence interval; IM: Intramuscular; NRS: Numerical rating scales; PRISMA: Preferred reporting items for systematic reviews and meta-analyses; RR: Relative risk; SAE: Serious adverse events; SC: Subcutaneous; SL: Sublingual; TD: Transdermal; VAS: Visual-analogue scales; VRS: Verbal rating scales.

\section{Competing interest}

The authors declare that they have no conflicts of interest.

\section{Authors' contributions}

PNY: conceived the study; CN, PNY: reviewed the literature, extracted data; CN, PNY, KA: analyzed; KA, PNY, CN: interpreted; CN drafted the manuscript; PNY: Critically revised the manuscript for intellectual contents. All authors read and approved the final version.

\section{Acknowledgements}

We are grateful to the participants and researchers of the primary studies identified for the present review. We also thankfully acknowledge support from International Medical University, Malaysia (partly from ID: BMS 1-01/2011 
(01) for the purchase of articles). We wish to thank the anonymous reviewers and editors for their comments and helpful input to improve the manuscript.

\section{Received: 11 December 2013 Accepted: 11 February 2014} Published: 13 February 2014

\section{References}

Al-Tawil N, Odar-Cederlof I, Berggren AC, Johnson HE, Persson J (2013) Pharmacokinetics of transdermal buprenorphine patch in the elderly. Eur J Clin Pharmacol 69:143-149

Aurilio C, Pace MC, Pota V, Sansone P, Barbarisi M, Grella E et al (2009) Opioids switching with transdermal systems in chronic cancer pain. J Exp Clin Cancer Res 28:61

Bohme K, Likar R (2003) Efficacy and tolerability of a new opioid analgesic formulation, buprenorphine transdermal therapeutic system (TDS) in the treatment of patients with chronic pain. A randomised, double blind, placebo-controlled study. Pain Clin 15:193-202

Bono AV, Cuffari S (1997) Effectiveness and tolerance of tramadol in cancer pain. A comparative study with respect to buprenorphine. Drugs 53:40-49

Brema F, Pastorino G, Martini MC, Gottlieb A, Luzzani M, Libretti A et al (1996) Oral tramadol and buprenorphine in tumour pain. Int J Clin Pharmacol Res 16:109-116

Cherny N, Ripamonti C, Pereira J, Davis C, Fallon M, McQuay H et al (2001) Strategies to manage the adverse effects of oral morphine: an evidence-based report. J Clin Oncol 19:2542-2554

De Conno F, Ripamonti C, Tamburini M, Ventafridda V (1987) Buprenorphine in cancer pain: cross comparison with pentazocine. Minerva Med 78:1177-1181

Deandrea S, Corli O, Moschetti I, Apolone G (2009) Managing severe cancer pain: the role of transdermal buprenorphine: a systematic review. Ther Clin Risk Manag 5:707-718

Dini D, Fassio T, Gottlieb A, Gini M (1986) Controlled study of the analgesic effect and tolerability of buprenorphine in cancer patients. Minerva Med 77:93-104

Fudala PJ, Bridge TP, Herbert S, Williford WO, Chiang CN, Jones K et al (2003) Office based treatment of opiate addiction with a sublingual-tablet formulation of buprenorphine and naloxone. New Engl J Med 349:949-958

Hanks GW (1991) Opioid responsive and opioid-non-responsive pain in cancer. Br Med Bull 47:718-731

Hanks GW, Kaasa S, Mercadante S, Olarte JMN, Poulain P, Radbruch L (2001) Morphine and alternative opioids in cancer pain: the EAPC recommendations. Expert working group of the research network of the European association for palliative care. Br J Cancer 84:587-593

Higgins JPT, Green S (2011) Cochrane Handbook for Systematic Reviews of Interventions Version 5.1.0 (updated March 2011). The Cochrane Collaboration

ICRC (International Agency for Research on Cancer) (2012) Latest world cancer statistics - GLOBOCAN 2012: Estimated cancer incidence, mortality and prevalence worldwide in 2012., http://www.iarc.fr/en/media-centre/pr/2013/pdfs/pr223_E.pdf. Accessed 15 Jan 2014

Kjaer M, Henriksen H, Knudsen J (1982) A comparative study of intramuscular buprenorphine and morphine in the treatment of chronic pain of malignant origin. Br J Clin Pharmacol 13:487-492

Levy MH (1996) Pharmacologic treatment of cancer pain. New Engl J Med 335:1124-1132

Likar R, Lorenz V, Korak-Leiter M, Kager I, Sittl R (2007) Transdermal buprenorphine patches applied in a 4-day regimen versus a 3-day regimen: a single-site, phase III, randomised, open-label, cross-over comparison. Clin Ther 29:1591-1606

Lutfy K, Cowan A (2004) Buprenorphine: a unique drug with complex pharmacology. Curr Neuropharmacol 2:395-402

Mattick RP, Kimber J, Breen C, Davoli M (2008) Buprenorphine maintenance versus placebo or methadone maintenance for opioid dependence. Cochrane Database Syst Rev 16(2), CD002207

Moher D, Liberati A, Tetzlaff J, Altman DG, the PRISMA Group (2009) Preferred reporting items for systematic reviews and meta-analyses: the PRISMA statement. PLoS Med 6:e1000097

Naing CM, Aung K, Yeoh PN (2012) Buprenorphine for treating cancer pain (Protocol). Cochrane Database Syst Rev Issue 1:CD009596, doi: 10.1002/ 14651858.CD009596

Naing C, Aung K, Racloz V, Yeoh PN (2013) Safety and efficacy of transdermal buprenorphine for thye relief of cancer pain. I Cancer Res Clin Oncol 139:1963-1970
Noda J, Umeda S, Arai T, Harima A, Mori K (1989) Continuous subcutaneous infusion of buprenorphine for cancer pain control. Clin J Pain 5:147-152

Pace MC, Passavanti MB, Grella E, Mazzariello L, Maisto M, Barbarisi M et al (2007) Buprenorphine in long-term control of chronic pain in cancer patients. Front Biosci 12:1291-1299

Poulain P, Denier W, Douma J, Hoerauf K, Samija M, Sopata M et al (2008) Efficacy and safety of transdermal buprenorphine: a randomised, placebo-controlled trial in 289 patients with severe cancer pain. J Pain Symptom Manage 36:117-125

Quigley C (2004) Opioid switching to improve pain relief and drug tolerability. Cochrane Database Syst Rev Issue 3:CD004847, doi: 0.1002/14651858. CD004847

Reisfield GM, Wilson GR (2007) Rational use of sublingual opioids in palliative medicine. Palliat Med 10:465-475

Robbie DS (1979) A trial of sublingual buprenorphine in cancer pain. Br J Clin Pharmacol 7:315S-317S

Rossitto M, Pante S, Manfre A, Ciccolo A (2009) Post-operative analgesia in case of ano-rectal diseases. Ann Ital Chir 80:459-461

Sittl R, Griessinger N, Likar R (2003) Analgesic efficacy and tolerability of transdermal buprenorphine in patients with inadequately controlled chronic pain related to cancer and other disorders: a multicenter, randomised, double-blind, placebo controlled trial. Clin Ther 25:150-168

Skaer TL (2006) Transdermal opioids for cancer pain. Health Qual Life Outcomes 4:24

Sorge J, Sittl R (2004) Transdermal buprenorphine in the treatment of chronic pain: results of a phase III, multicenter, randomised, double-blind, placebo-controlled study. Clin Ther 26:1808-1820

Straube S, Derry S, McQuay HJ, Moore RA (2008) Enriched enrolment: definition and effects of enrichment and dose in trials of pregabalin and gabapentin in neuropathic pain. A systematic review. Br J Clin Pharmacol 66:266-275

Taguchi T (1982) Effect of a long-acting analgesic, buprenorphine on cancer pain-a single-blind crossover comparison with pentazocine. Gan To Kagaku Ryoho 9:250-257

Tassinari D, Drudi F, Rosati M, Maltoni M (2011) Transdermal opioids as front line treatment of moderate to severe cancer pain: a systemic review. Palliat Med 25:478-487

Ventafridda V, De Conno F, Guarise G, Tamburini M, Savio G (1983) Chronic analgesic study on buprenorphine action in cancer pain. Comparison with pentazocine. Arzneimittelforschung 33:587-590

WHO (2011) Global status report on non-communicable diseases 2010. Burden: mortality, morbidity and risk factors. In: Description of the global burden of NCDs, their risk factors and determinants. WHO, Geneva, pp 1-23

WHO (World Health Organization) (1996) Cancer Pain Relief, 2nd edn. World Health Organization, Geneva

WHO (World Health Organization) (2009) WHO Guidelines: Cancer Control. WHO, Geneva

Wiffen PJ, Edwards JE, Barden J, McQuay HJM (2003) Oral morphine for cancer pain. Cochrane Database Syst Rev Issue 4:CD003868, doi: 10.1002/14651858. CD003868

Wirz S, Wittmann M, Schenk M, Schroeck A, Schaefer N, Mueller M et al (2009) Gastrointestinal symptoms under opioid therapy:a prospective comparison of oral sustained-release hydromorphone, transdermal fentanyl, and transdermal buprenorphine. Eur J Pain 13:737-743

Wolff RF, Aune D, Truyers C, Hernandez AV, Misso K, Riemsma R et al (2012) Systematic review of efficacy and safety of buprenorphine versus fentanyl or morphine in patients with chronic moderate to severe pain. Curr Med Res Opin 28:833-845

Yaksh TL, Wallace MS (2011) Opioids, analgesia, and pain management. In: Brunton LL, Chabner BA, Knollmann BC (eds) Goodman \& Gilman's The Pharmacological Basis of Therapeutics, 12th edn. The McGraw-Hill

Zhang W, Ramamoorthy Y, Tyndale RF, Sellers EM (2003) Interaction of buprenorphine and its metabolite norbuprenorphine with cytochromes p450 in vitro. Drug Metab Dispos 31:768-772

doi:10.1186/2193-1801-3-87

Cite this article as: Naing et al:: A meta-analysis of efficacy and tolerability of buprenorphine for the relief of cancer pain. SpringerPlus 2014 3:87. 